\title{
Estradiol-Induced Object Memory Consolidation in Middle-Aged Female Mice Requires Dorsal Hippocampal Extracellular Signal-Regulated Kinase and Phosphatidylinositol 3-Kinase Activation
}

\author{
Lu Fan, ${ }^{1}$ Zaorui Zhao, ${ }^{1}$ Patrick T. Orr, ${ }^{1}$ Cassie H. Chambers, ${ }^{1}$ Michael C. Lewis,${ }^{3}$ and Karyn M. Frick ${ }^{1,2}$ \\ ${ }^{1}$ Department of Psychology and ${ }^{2}$ Interdepartmental Neuroscience Program, Yale University, New Haven, Connecticut 06520, and ${ }^{3}$ Stanley Center for \\ Psychiatric Research, Broad Institute of Massachusetts Institute of Technology and Harvard University, Cambridge, Massachusetts 02142
}

We previously demonstrated that dorsal hippocampal extracellular signal-regulated kinase (ERK) activation is necessary for $17 \beta$ estradiol $\left(E_{2}\right)$ to enhance novel object recognition in young ovariectomized mice (Fernandez et al., 2008). Here, we asked whether $E_{2}$ has similar memory-enhancing effects in middle-aged and aged ovariectomized mice, and whether these effects depend on ERK and phosphatidylinositol 3-kinase (PI3K)/Akt activation. We first demonstrated that intracerebroventricular or intrahippocampal $\mathrm{E}_{2}$ infusion immediately after object recognition training enhanced memory consolidation in middle-aged, but not aged, females. The $\mathrm{E}_{2}$-induced enhancement in middle-aged females was blocked by intrahippocampal inhibition of ERK or PI3K activation. Intrahippocampal or intracerebroventricular $\mathrm{E}_{2}$ infusion in middle-aged females increased phosphorylation of $\mathrm{p} 42 \mathrm{ERK}$ in the dorsal hippocampus 15 min, but not $5 \mathrm{~min}$, after infusion, an effect that was blocked by intrahippocampal inhibition of ERK or PI3K activation. Dorsal hippocampal PI3K and Akt phosphorylation was increased 5 min after intrahippocampal or intracerebroventricular $\mathrm{E}_{2}$ infusion in middle-aged, but not aged, females. Intracerebroventricular $\mathrm{E}_{2}$ infusion also increased PI3K phosphorylation after 15 min, and this effect was blocked by intrahippocampal PI3K, but not ERK, inhibition. These data demonstrate for the first time that activation of dorsal hippocampal PI3K/ Akt and ERK signaling pathways is necessary for $\mathrm{E}_{2}$ to enhance object recognition memory in middle-aged females. They also reveal that similar dorsal hippocampal signaling pathways mediate $\mathrm{E}_{2}$-induced object recognition memory enhancement in young and middle-aged females and that the inability of $\mathrm{E}_{2}$ to activate these pathways may underlie its failure to enhance object recognition in aged females.

\section{Introduction}

Although recent clinical trials report that hormone therapy increases risks of global cognitive decline and dementia in postmenopausal women (Rapp et al., 2003; Shumaker et al., 2004), other studies demonstrate that estrogen therapy can reduce risks of cognitive decline and dementia in younger, recently menopausal, women (Henderson et al., 2005). These findings support the "critical period hypothesis" that posits that estrogen therapy preserves cognition only when initiated near menopause onset (Sherwin and Henry, 2008). Although compelling, the neurobiological mechanisms underlying this critical period have not been clearly elucidated in women or animal models. Because current estrogen therapies are associated with negative health outcomes (Rossouw et al., 2002), understanding the neural mechanisms through which estrogens protect memory in menopausal females could be instrumental to developing safer and more effective estrogen treatments for reducing age-related cognitive decline.

\footnotetext{
Received Sept. 2, 2009; revised Jan. 11, 2010; accepted Jan. 25, 2010.

This project was supported by Yale University and National Institute on Aging Grant AG022525 (K.M.F.).

Correspondence should be addressed to Dr. Karyn M. Frick, Department of Psychology, Yale University, P.O. Box 208205, New Haven, CT 06520. E-mail: karyn.frick@yale.edu.

DOI:10.1523/JNEUROSCI.4333-09.2010

Copyright $\odot 2010$ the authors $\quad 0270-6474 / 10 / 304390-11 \$ 15.00 / 0$
}

To this end, we recently demonstrated that activation of the extracellular signal-regulated kinase/mitogen-activated protein kinase (ERK/MAPK) signaling cascade in the dorsal hippocampus is necessary for the potent estrogen $17 \beta$-estradiol $\left(\mathrm{E}_{2}\right)$ to enhance novel object recognition in young ovariectomized mice (Fernandez et al., 2008). In this study, a single intraperitoneal injection of $\mathrm{E}_{2}$ given immediately after training significantly enhanced object recognition tested $48 \mathrm{~h}$ later and increased phosphorylation of the $\mathrm{p} 42$ isoform of ERK in the dorsal hippocampus $1 \mathrm{~h}$ after a subsequent injection (Fernandez et al., 2008). These effects were blocked by inhibiting MAPK kinase (MEK), the exclusive upstream activator of ERK (Fernandez et al., 2008). Posttraining intraperitoneal $\mathrm{E}_{2}$ injection also enhances $48 \mathrm{~h}$ object recognition in middle-aged, but not aged, ovariectomized mice (Gresack et al., 2007a,b), raising the possibility that age-related alterations in the ability of $\mathrm{E}_{2}$ to activate cell signaling underlie its differential effects on object memory in aging females. However, it is unknown whether $\mathrm{E}_{2}$ modulates object memory via similar signaling mechanisms in the aging female brain, given the myriad of age-related alterations that affect the hippocampus. Indeed, $\mathrm{E}_{2}$ protects against the ovariectomy-induced decrease in phosphorylated p42 ERK levels in young, but not aged, female rats (Bi et al., 2003). Nevertheless, whether $E_{2}$ increases hippocampal ERK ac- 
tivation in middle-aged rodents has not been examined, so it is unclear whether ERK activation mediates the beneficial effects of $\mathrm{E}_{2}$ on object recognition at this age.

Furthermore, ERK can be activated by other signaling cascades that are critical for hippocampal-dependent memory formation, including phosphatidylinositol 3-kinase (PI3K)/Akt (Chen et al., 2005). PI3K is crucial for hippocampal plasticity and object recognition (Kelly and Lynch, 2000; Lin et al., 2001; Horwood et al., 2006), is rapidly activated by $\mathrm{E}_{2}$ (Yokomaku et al., 2003; Mannella and Brinton, 2006), and is vital for neuroprotection (Singh, 2001), which could be critically important for the aging brain. As such, hippocampal PI3K/Akt signaling may play a pivotal role in $\mathrm{E}_{2}$-induced object recognition enhancement in aging females, perhaps by activating p42 ERK.

The present study determined whether dorsal hippocampal ERK and PI3K activation are necessary for the beneficial effects of $\mathrm{E}_{2}$ on object recognition in aging females. The data provide the first evidence that dorsal hippocampal PI3K and ERK activation is necessary for $E_{2}$ to enhance object memory consolidation in middle-aged female mice and that the inability of $\mathrm{E}_{2}$ to activate these enzymes in aged females may underlie its failure to enhance object recognition in advanced aging.

\section{Materials and Methods}

Subjects. Young ( 3 months old), middle-aged (17 months old), and aged (21 months old) female C57BL/6 mice were obtained from the National Institutes on Aging colony at Charles River Laboratories. Mice were housed four to five per cage until surgery and were handled briefly before use. Mice were maintained on a $12 \mathrm{~h}$ light/dark cycle and had ad libitum access to food and water. All procedures followed the National Institutes of Health Guide for the Care and Use of Laboratory Animals and were approved by Yale University Animal Care and Use Committee.

Surgery. Mice were ovariectomized and implanted with intracranial guide cannulae in the same surgical session as described previously (Fernandez et al., 2008; Lewis et al., 2008). All mice were implanted with stainless-steel guide cannulae (Plastics One) aimed at the dorsal hippocampus (bilaterally), dorsal third ventricle, or both brain regions. Mice were anesthetized with isoflurane gas (5\% for induction, $2 \%$ for maintenance). Using a stereotaxic apparatus (David Kopf Instruments), guide cannulae (C232GC, 26 gauge; Plastics One) with inserted dummy cannulae (C232DC) were directed toward the dorsal hippocampus $[-1.7 \mathrm{~mm}$ posterior to bregma, $\pm 1.5 \mathrm{~mm}$ lateral to midline, $-2.3 \mathrm{~mm}$ (injection site) ventral to skull surface], dorsal third ventricle $[-0.5 \mathrm{~mm}$ posterior to bregma, \pm 0.0 lateral to the midline, -3.0 (injection site) ventral to the skull surface], or both the hippocampus and dorsal third ventricle (triple guide; same coordinates as above for both regions) (Paxinos and Franklin, 2003). Each cannula was fixed to the skull with dental cement that also served to close the wound. Mice recovered 5-7 d before testing or drug treatment.

Drugs and infusions. Cyclodextrin-encapsulated $\mathrm{E}_{2}$ (Sigma-Aldrich) was dissolved in physiological saline to a dose of $5.0 \mu \mathrm{g} / 0.5 \mu \mathrm{l}$ and infused at $0.5 \mu \mathrm{l} / \mathrm{min}$ for $1 \mathrm{~min} / \mathrm{side}$ of the dorsal hippocampus. This dose in young ovariectomized mice infused into the dorsal hippocampus facilitates object memory consolidation (Fernandez et al., 2008). Intracerebroventricular infusions were conducted at the same speed for $2 \mathrm{~min}$. The vehicle, 2-hydroxypropyl- $\beta$-cyclodextrin (Sigma-Aldrich), was dissolved in saline to the same concentration of cyclodextrin as in the cyclodextrin- $\mathrm{E}_{2}$ solution.

To demonstrate that $\mathrm{E}_{2}$-enhanced object recognition consolidation was dependent on dorsal hippocampal ERK activation, the MEK inhibitor U0126 [1,4-diamino-2,3-dicyano-1,4-bis (o-aminophenylmercapto) butadiene] (Promega), at a concentration of $0.5 \mu \mathrm{g} / 0.5 \mu \mathrm{l}$ in $50 \%$ dimethylsulfoxide (DMSO) in saline, was infused at a rate of $0.5 \mu \mathrm{l} / \mathrm{min}$ for $1 \mathrm{~min} / \mathrm{side}$ of dorsal hippocampus, alone or concurrently with intracerebroventricular $\mathrm{E}_{2}$ infusion. In young ovariectomized mice, intrahippocampal infusion of this dose of U0126 does not block ob- ject recognition tested $24 \mathrm{~h}$ after training (Fernandez et al., 2008). The vehicle control for U0126 was 50\% DMSO in saline.

To demonstrate that $\mathrm{E}_{2}$-enhanced object recognition consolidation was dependent on dorsal hippocampal PI3K activation, the PI3K inhibitor LY294002 [2-(4-morpholinyl)-8-phenyl-1(4 H)-benzopyran-4-one] (Cell Signaling Technology), which inhibits phosphorylation of the $\mathrm{p} 85$ regulatory subunit of PI3K (Geltz and Augustine, 1998), was dissolved in $100 \%$ DMSO to $3 \mu \mathrm{g} / \mu \mathrm{l}$ as a stock solution and then serially diluted in physiological saline for infusion of various doses. We first wanted to determine a dose of LY294002 that did not impair object recognition tested $24 \mathrm{~h}$ after training. Previous studies in adult rats have shown that posttraining infusions of LY294002 at very low doses (equal to or $<0.75$ $\mathrm{ng} /$ side of hippocampus) do not cause retrograde amnesia in a stepdown inhibitory avoidance task (Barros et al., 2001). Therefore, we infused very low doses in our $24 \mathrm{~h}$ pilot study; all doses $(0.5,0.005$, and $0.0005 \mu \mathrm{g} / \mathrm{side}$ of the hippocampus) of LY294002 were infused at a rate of $0.5 \mu \mathrm{l} / \mathrm{min}$ and a volume of $0.5 \mu \mathrm{l} /$ side. Only a dose that did not impair $24 \mathrm{~h}$ object recognition was used in subsequent studies with $\mathrm{E}_{2}$. The vehicle control for LY294002 was 50\% DMSO in saline.

During drug infusions, mice were gently restrained. Dummy cannulae were replaced with injection cannulae (C232I; intrahippocampal, 26 gauge, extending $0.8 \mathrm{~mm}$ beyond the $1.5 \mathrm{~mm}$ guide, intracerebroventricular, 28 gauge, extending $1.0 \mathrm{~mm}$ beyond the $2.0 \mathrm{~mm}$ guide) attached to polyethylene tubing (PE50) connected to a $10 \mu$ l Hamilton syringe. Infusions were controlled by a microinfusion pump (KDS 100; KD Scientific). Infusion cannulae remained in place for $1 \mathrm{~min}$ after infusion to prevent diffusion backup the cannula track. For behavioral testing, all mice were infused immediately after object recognition training.

Object recognition. The object recognition task was conducted as described previously (Frick and Gresack, 2003; Fernandez and Frick, 2004) and was used to assess nonspatial hippocampal-dependent memory (Clark et al., 2000; Baker and Kim, 2002). The task consisted of habituation, training, and testing phases conducted on separate days. During habituation, mice were allowed to freely explore an empty white box (60 $\mathrm{cm}$ width $\times 60 \mathrm{~cm}$ length $\times 47 \mathrm{~cm}$ height) for $5 \mathrm{~min}$. No data were recorded. Twenty-four hours later, mice were rehabituated in the same box for $1 \mathrm{~min}$ and then placed in a holding cage while two identical objects were placed in the left and right corners ( $\sim 5 \mathrm{~cm}$ from the walls) of the box. Mice were then immediately placed back into the box and allowed to freely investigate until they accumulated a total of $30 \mathrm{~s}$ exploring the objects. Exploration was recorded when the front paws or nose contacted either object. Mice were then immediately infused and returned to their home cage (or in some cases, killed 15 min later). After 24 or $48 \mathrm{~h}$, object recognition was tested, using the same procedure as in training except that a novel object was substituted for one of the familiar training objects. Novel object location was counterbalanced across mice. Time spent with each object was recorded. Mice inherently prefer to explore novel objects; thus, a preference for the novel object [more time than chance (15 s) with the novel object] indicates intact memory for the familiar object. The use of $30 \mathrm{~s}$ total exploration time rather than a fixed trial duration minimizes confounding influences of group differences in activity. Young ovariectomized mice remember the familiar object after $24 \mathrm{~h}$, but not $48 \mathrm{~h}$ (Gresack et al., 2007a), allowing impairing effects of drugs to be observed using the $24 \mathrm{~h}$ delay and enhancing effects of drugs to be observed using the $48 \mathrm{~h}$ delay. Elapsed time to accumulate $30 \mathrm{~s}$ of exploration was recorded to control for group differences in activity levels, but none were observed in any experiment (Table 1).

Western blotting. Mice were decapitated 5 or 15 min after intracranial infusions or $15 \mathrm{~min}$ after object recognition training, and the dorsal hippocampus was immediately dissected bilaterally on ice and frozen at $-80^{\circ} \mathrm{C}$ until homogenized. Western blotting was conducted as described previously (Fernandez et al., 2008; Lewis et al., 2008). Briefly, all tissue samples were resuspended 1:50 w/v in lysis buffer and homogenized with a probe sonicator (Branson Sonifier 250). Homogenates were electrophoresed on $10 \%$ Tris- $\mathrm{HCl}$ gels and blotted to Immobilon-P polyvinylidene fluoride membranes (Millipore Corporation). Western blots were blocked and incubated with either anti-phospho-p44/42 MAPK (1:2000), anti-phospho-PI3K (1:1000), anti-phospho-Akt (1:1000), or total p44/42 MAPK (1:2000), total PI3K (1:1000), total Akt (1:1000) primary antibodies 
Table 1. Mean \pm SEM elapsed time during object recognition testing

\begin{tabular}{|c|c|c|c|}
\hline Age & Delay & Treatment & Elapsed time (s) \\
\hline \multirow{2}{*}{ Middle-aged } & \multirow[t]{2}{*}{$24 \mathrm{~h}$} & Vehicle & $387.95 \pm 71.07$ \\
\hline & & IH U0126 & $471.91 \pm 135.11$ \\
\hline \multirow[t]{3}{*}{ Middle-aged } & \multirow[t]{3}{*}{$24 \mathrm{~h}$} & IH LY294002, $0.0005 \mu \mathrm{g}$ & $270.22 \pm 31.47$ \\
\hline & & IH LY294002, $0.005 \mu \mathrm{g}$ & $291.88 \pm 52.51$ \\
\hline & & IHLY294002, $0.5 \mu \mathrm{g}$ & $468.25 \pm 64.55$ \\
\hline \multirow[t]{5}{*}{ Middle-aged } & \multirow[t]{5}{*}{$48 \mathrm{~h}$} & Vehicle & $342.43 \pm 58.42$ \\
\hline & & $\mathrm{ICVE}_{2}$ & $489.92 \pm 76.78$ \\
\hline & & $\mathrm{IHE}_{2}$ & $455.91 \pm 110.46$ \\
\hline & & $\mathrm{ICVE}_{2}+\mathrm{IH} \mathrm{U} 0126$ & $402.75 \pm 79.37$ \\
\hline & & $\mathrm{ICVE}_{2}+\mathrm{IH} L \mathrm{~L} 294002$ & $441.78 \pm 67.32$ \\
\hline \multirow[t]{3}{*}{ Aged } & \multirow[t]{3}{*}{$48 \mathrm{~h}$} & Vehicle & $322.61 \pm 29.73$ \\
\hline & & $\mathrm{ICVE}_{2}$ & $297.73 \pm 39.48$ \\
\hline & & $\mathrm{IHE}_{2}$ & $294.25 \pm 58.36$ \\
\hline
\end{tabular}

ICV, Intracerebroventricular; IH, intrahippocampal.

(Cell Signaling Technology) overnight. Blots were then incubated with the appropriate secondary antibody conjugated to horseradish peroxidase (Cell Signaling Technology) and developed using West Dura chemiluminescent substrate (Pierce). Blots were then stripped and reprobed with antibodies for total p44/42 MAPK, total PI3K, or total Akt antibodies for phospho-protein normalization or with anti- $\beta$-actin antibody (1:5000; Sigma) for total protein normalization. Densitometry was conducted using Kodak 1D 3.6 software (Kodak Scientific Imaging Systems) on the Kodak Image Station 440 CF (Eastman Kodak).

Immunocytochemistry. In middle-aged mice, one side of the dorsal hippocampus was infused with vehicle, and the other side was infused with $\mathrm{E}_{2}$. Fifteen minutes later, the mice were anesthetized with sodium pentobarbital (50 $\mathrm{mg} / \mathrm{kg}$, i.p.) and perfused intracardially with $0.9 \% \mathrm{sa}-$ line, followed by $4 \%$ paraformaldehyde in $0.1 \mathrm{~m}$ phosphate buffer. Brains were postfixed and cryoprotected, frozen, and stored at $-80^{\circ} \mathrm{C}$. Before sectioning, a notch was placed along the left cortex to maintain laterality throughout the analyses. Forty micrometer frozen, serial, coronal sections were cut throughout the brain and stored in cryoprotectant for immunocytochemistry on free-floating sections. Every sixth section was collected and immunostained with phospho-p44/42 MAPK antibody as in a previous study (Fan et al., 2008; Tsuda et al., 2008) using Vectastain $\mathrm{ABC}$ kit (Vector Laboratories). Briefly, sections were blocked in 3\% normal goat serum and incubated in rabbit anti-phospho-p44/42 MAPK antibody (1:1000; Cell Signaling Technology) overnight at room temperature. For control sections, the primary antibody was omitted. Sections were then incubated in biotinylated goat anti-rabbit IgG (1:200) for $1 \mathrm{~h}$ at room temperature, washed, and incubated in avidin-biotin solution (Vectastain ABC kit; 1:500; Vector Laboratories) in Tris-buffered saline for $1 \mathrm{~h}$ at room temperature. Sections were reacted with $3^{\prime}, 3^{\prime}$ diaminobenzidine solution (Sigma), washed, mounted on gelatin-coated slides, air dried, dehydrated, cleared, and coverslipped.

Statistical analyses. For object recognition data, separate one-sample $t$ tests were performed for each group to determine whether the time spent with the novel object differed from $15 \mathrm{~s}$. This analysis was used because time spent with the objects is not independent; time spent with one object reduces time spent with the other object (Gresack and Frick, 2004, 2006). For Western blotting experiments comprising multiple groups, differences between vehicle and treatment groups were evaluated using one-way ANOVA, followed by Fisher's least significant difference (LSD) post hoc tests. For Western blotting experiments with only two groups, separate two-tailed unpaired Student's $t$ tests were performed between the vehicle and treatment group. For experiments examining the effects of object recognition training on phosphorylated and total protein levels, two-way ANOVA was first used to examine the effects of age and training, followed by Fisher's LSD post hoc tests. Next, two-tailed unpaired Student's $t$ tests were performed between the training groups within each age to examine effects of training on protein levels within each age. Significance was determined at $p<0.05$.

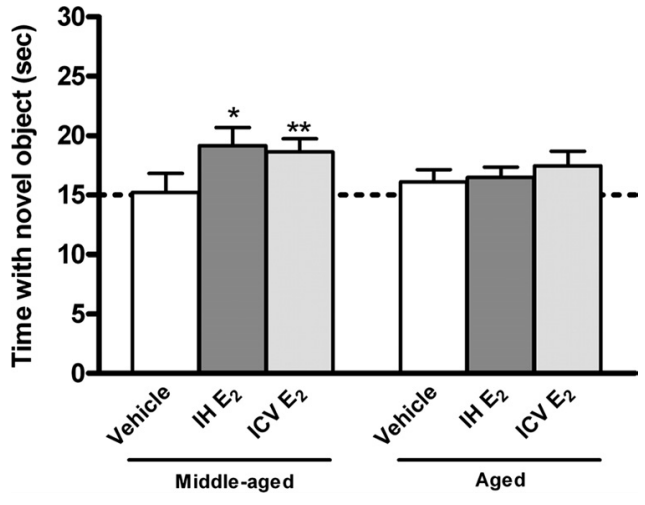

Figure 1. Object recognition in middle-aged and aged female mice. Middle-aged females receiving immediate posttraining intrahippocampal (IH) or intracerebroventricular (ICV) infusions of $\mathrm{E}_{2}$ (intrahippocampal, $5 \mu \mathrm{g} /$ side; intracerebroventricular, $10 \mu \mathrm{g}$ total) but not vehicle spent significantly more time with the novel object than chance (dashed line at $15 \mathrm{~s}$ ) $48 \mathrm{~h}$ after training, demonstrating memory for the familiar object. In contrast, aged females receiving vehicle or the same doses of intrahippocampal or intracerebroventricular $E_{2}$ spent no more time than chance with the novel object. Each bar represents the mean \pm SEM time spent with the novel object $\left({ }^{*} p<0.05,{ }^{* *} p<0.01\right.$ relative to chance).

\section{Results}

Intracranial infusions of estradiol enhance object recognition in middle-aged, but not aged, female mice

We previously demonstrated that a single posttraining intraperitoneal injection of $\mathrm{E}_{2}$ enhances object recognition in middleaged, but not aged, ovariectomized mice (Gresack et al., 2007a,b). One possible reason for the lack of effect in aged females is that too little of the systemically injected hormone reached the dorsal hippocampus to be behaviorally effective. Thus, we first sought to determine whether direct intrahippocampal or intracerebroventricular infusions of the same dose of posttraining $E_{2}$ that enhances object recognition in young ovariectomized mice (Fernandez et al., 2008) could also enhance object recognition in middle-aged ( $n=8-16$ per group) and aged ( $n=9$ per group) ovariectomized mice. Immediately after training, mice were infused with vehicle or $\mathrm{E}_{2}$ into the dorsal hippocampus (5 $\mu \mathrm{g} /$ side) or dorsal third ventricle (10 $\mu \mathrm{g}$ total), and retention was tested $48 \mathrm{~h}$ later. In middle-aged females (Fig. 1), both intrahippocampal and intracerebroventricular $\mathrm{E}_{2}$ infusions significantly increased the time spent with the novel object relative to chance $(15 \mathrm{~s})\left(t_{(7)}=2.72, p<0.05\right.$ and $t_{(15)}=3.26, p<0.01$, respectively), suggesting that both intrahippocampal and intracerebroventricular $\mathrm{E}_{2}$ enhanced novel object recognition in middle-aged female mice. Vehicle-treated mice did not exhibit a preference for the novel object $\left(t_{(9)}=0.13, p>0.05\right)$. In contrast to the beneficial effects of $E_{2}$ in middle-aged females, aged females were unaffected by $E_{2}$. Neither the vehicle-treated nor the $E_{2}$-treated groups exhibited a preference for novel object $48 \mathrm{~h}$ after training $\left.t_{(8)}=1.10-1.93, p>0.05\right)$ (Fig. 1), suggesting that doses of intracranially infused $E_{2}$ that enhance object recognition in young and middle-aged females do not affect object memory consolidation in aged females.

\section{Estradiol-induced enhancement of object recognition in middle-aged mice is dependent on dorsal hippocampal ERK activation}

To determine whether the beneficial effects of $E_{2}$ on object recognition in middle-aged females were dependent on dorsal hippocampal ERK activation, the MEK inhibitor U0126 was bilaterally infused into the dorsal hippocampus concurrently with 

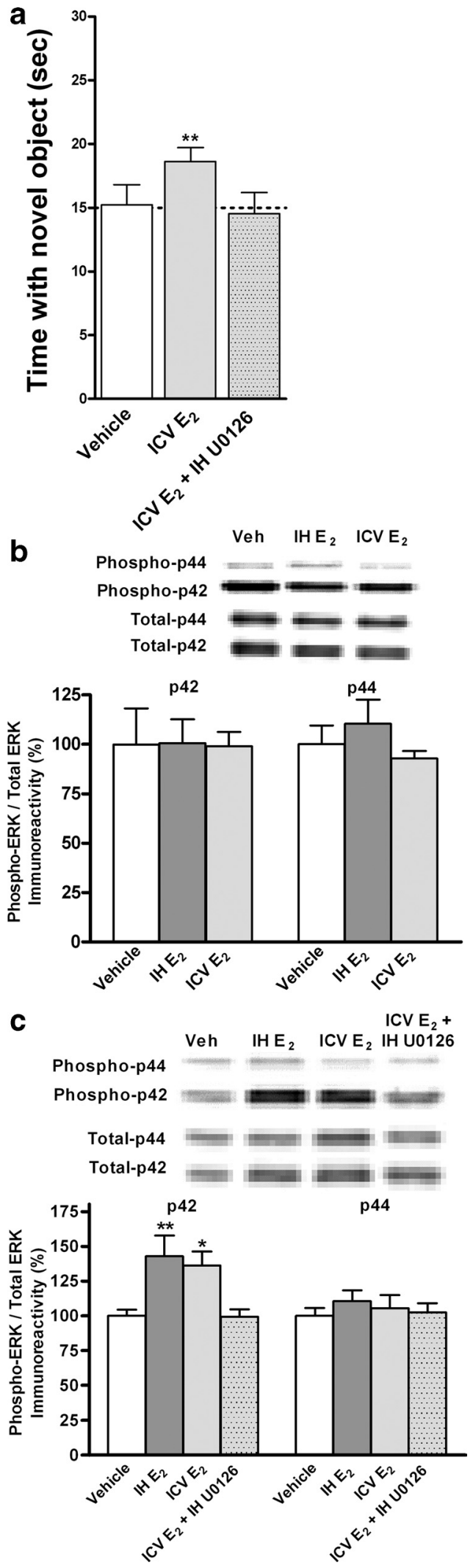

Figure 2. $\quad \boldsymbol{a}$, Intrahippocampal (IH) infusions of U0126 (0.5 $\mu \mathrm{g} / \mathrm{side})$ blocked the beneficial effects of intracerebroventricular (ICV) $E_{2}(10 \mu \mathrm{g})$ (vehicle and intracerebroventricular $E_{2}$ alone groups reprinted from Fig. 1). Mice receiving intracerebroventricular $E_{2}+$ intrahippocampal U0126 did not spend more time than chance with the novel object. Each bar represents the mean \pm SEM time spent with the novel object $\left({ }^{* *} p<0.01\right.$, relative to chance). $\boldsymbol{b}$, Five minutes after infusion, levels of p 42 and p44 ERK phosphorylation in the dorsal hippocampus were not affected by intrahippocampal or intracerebroventricular $E_{2}$ infusion. intracerebroventricular $\mathrm{E}_{2}$ infusion. To first demonstrate that effects of MEK inhibition on $\mathrm{E}_{2}$-induced enhancement of $48 \mathrm{~h}$ object recognition did not result from general prevention of memory formation in this task, we identified a dose of U0126 that did not interfere with object recognition at a shorter delay. Previously, we showed in young ovariectomized mice that immediate posttraining infusion of U0126 into the dorsal hippocampus, at a dose of $0.5 \mu \mathrm{g} / \mathrm{side}$, did not impair object recognition tested $24 \mathrm{~h}$ after training (Fernandez et al., 2008). Thus, we tested whether this dose of U0126 interfered with $24 \mathrm{~h}$ object recognition in middle-aged females. Mice were infused bilaterally into the dorsal hippocampus with vehicle $(n=10)$ or $0.5 \mu \mathrm{g}$ of $\mathrm{U} 0126$ $(n=8)$ immediately after training. Twenty-four hours later, both the vehicle and U0126 groups spent significantly more time with the novel object than chance $(19.45 \pm 1.27 \mathrm{~s}$ for vehicle and $20.52 \pm 0.6 \mathrm{~s}$ for U0126; $t_{(9)}=3.51, p<0.01 ; t_{(7)}=9.23, p<0.001$, respectively). These data suggest that $0.5 \mu \mathrm{g}$ of U0126 does not prevent general memory formation in this task in middle-aged females. Therefore, this dose was used in all subsequent studies.

We then examined whether intrahippocampal infusion of 0.5 $\mu \mathrm{g}$ of U0126 affected the $\mathrm{E}_{2}$-induced enhancement of object recognition by infusing U0126 bilaterally into the dorsal hippocampus concurrently with intracerebroventricular $\mathrm{E}_{2}$ infusion. As in our previous work with a membrane-impermeable form of $E_{2}$ (Fernandez et al., 2008), $\mathrm{E}_{2}$ was infused intracerebroventricularly in this study to provide $\mathrm{E}_{2}$ to the brain while preventing tissue damage from repeated infusions into the dorsal hippocampus. As shown in Figure $2 a$, the intracerebroventricular $\mathrm{E}_{2}$-induced enhancement in $48 \mathrm{~h}$ object recognition was completely blocked by intrahippocampal U0126 $\left(t_{(9)}=-0.27, p>0.05\right.$ relative to vehicle), suggesting that $\mathrm{E}_{2}$-induced facilitation of object recognition in middle-aged female mice is dependent on dorsal hippocampal ERK activation.

\section{Estradiol increases p42 ERK activation in the dorsal hippocampus $15 \mathrm{~min}$, but not $5 \mathrm{~min}$, after infusion in middle-aged females}

The fact that U0126 blocked the effects of $E_{2}$ on object recognition suggests that $\mathrm{E}_{2}$ increases ERK activation in the dorsal hippocampus of middle-aged females. Therefore, we next sought to determine whether and when that activation takes place. Previous work showed that p42/p44 ERK activation in the dorsal hippocampus is increased 5 min after intracerebroventricular $\mathrm{E}_{2}$ infusion in young male rats (Kuroki et al., 2000). Furthermore, we recently demonstrated that p $42 \mathrm{ERK}$ activation in the dorsal hippocampus is increased 5 min after dorsal hippocampal infusion of a membrane-impermeable form of $\mathrm{E}_{2}$ in young ovariectomized mice (Fernandez et al., 2008). As such, we examined whether intrahippocampal or intracerebroventricular $\mathrm{E}_{2}$ could increase ERK activation in middle-aged females $5 \mathrm{~min}$ after infusion. Middle-aged females received intrahippocampal or intracerebroventricular infusions of vehicle $(n=8)$ or $\mathrm{E}_{2}$ (intrahippocampal, $n=7$; intracerebroventricular, $n=6$ ), and the dorsal hippocampus was collected bilaterally 5 min later for measurement of phos-

$\leftarrow$

c, Fifteen minutes after infusion, levels of p42 ERK, but not p44 ERK, phosphorylation were significantly increased in the dorsal hippocampus by intrahippocampal (5 $\mu \mathrm{g} / \mathrm{side}$ ) or intracerebroventricular $(10 \mu \mathrm{g}) \mathrm{E}_{2}$ relative to vehicle controls $\left({ }^{*} p<0.05,{ }^{* *} p<0.01\right)$. The intracerebroventricular $E_{2}$-induced increase was blocked by intrahippocampal U0126 (0.5 $\left.\mu \mathrm{g} / \mathrm{side}\right)$. Phosphorylated p42/p44 protein levels were normalized to total p42/p44 protein levels. Each bar in $\boldsymbol{b}$ and $c$ represents the mean \pm SEM percentage change from vehicle controls. Insets in $\boldsymbol{b}$ and $c$ are representative Western blots showing phosphorylated and total p42 and p44 ERK protein levels. 
phorylated and total p42 and p44 ERK levels using Western blotting. Neither intrahippocampal nor intracerebroventricular $\mathrm{E}_{2}$ infusion affected phosphorylation of p42 $\operatorname{ERK}\left(F_{(2,18)}=0.39, p>0.05\right)$ or p44 ERK $\left(F_{(2,18)}=0.77, p>0.05\right)$ (Fig. $2 b$ ). This result led us to hypothesize that the temporal dynamics of ERK activation may differ in the young and aging female brain. Evidence for altered ERK activation as a result of aging comes from studies in which p42/p44 ERK activation in the hippocampus and basal forebrain of aged male rats is diminished relative to young males in response to growth factor treatment (Gooney et al., 2004; Williams et al., 2006, 2007). Therefore, we next examined ERK activation at a later time point, 15 min after infusion. To visualize where in the dorsal hippocampus this activation might occur, we infused mice $(n=4)$ on one side of the dorsal hippocampus with vehicle and the other side with $5 \mu \mathrm{g}$ of $\mathrm{E}_{2}$, perfused them $15 \mathrm{~min}$ later, and stained coronal sections for phosphop42/p44 ERK immunoreactivity. Immunoreactivity was increased primarily in the hilus of the dentate gyrus and in CA3. In the hilus (Fig. $3 c, d$ ), $\mathrm{E}_{2}$ treatment increased phospho-ERK immunostaining in cells and processes relative to vehicle; estrogen receptors $\alpha$ and $\beta$ (ER $\alpha$ and $\mathrm{ER} \beta$ ) have been reported in interneurons, glia, dendrites, axons, and axon terminals of the hilus (Milner et al., 2001, 2005). In CA3 (Fig. $3 e, f$ ), increased immunolabeling was evident only in processes in the $\mathrm{E}_{2}$-treated side compared with vehicle; $\mathrm{ER} \alpha$ and/or ER $\beta$ have been localized to dendrites, dendritic spines, axons, and axon terminals of CA3 (Milner et al., 2001, 2005). Given the observed increase in ERK phosphorylation evident at $15 \mathrm{~min}$ immunocytochemically, we then quantified this increase using Western blotting. In addition to mice infused with vehicle and $\mathrm{E}_{2}$ alone, a fourth group was added that received intracerebroventricular $E_{2}$ plus intrahippocampal U0126. The main effect of treatment was significant for p42 ERK phosphorylation $\left(F_{(3,22)}=6.33, p<\right.$ $0.01)$ but not p44 ERK phosphorylation $\left(F_{(3,22)}=0.39, p>0.05\right)$ (Fig. 2c). Both intrahippocampal $\mathrm{E}_{2}(n=6)$ and intracerebroventricular $\mathrm{E}_{2}(n=6)$ infusions significantly increased dorsal hippocampal phosphorylated p42 ERK levels relative to vehicle $(n=7$; $p<0.01$ and $p<0.05$, respectively) (Fig. $2 c$ ). The intracerebroventricular $E_{2}$-induced increase in $\mathrm{p} 42$ ERK phosphorylation was completely blocked by intrahippocampal infusion of U0126 ( $n=7 ; p>0.05$ relative to vehicle) (Fig. $2 c$ ).

\section{Estradiol increases PI3K and Akt activation in the dorsal} hippocampus 5 min after infusion in middle-aged females The PI3K/Akt pathway, which can activate ERK (Chen et al., 2005), is also critical for hippocampal synaptic plasticity and memory formation (Kelly and Lynch, 2000; Lin et al., 2001; Horwood et al., 2006) and can be activated in vitro within minutes of $\mathrm{E}_{2}$ treatment (Yokomaku et al., 2003; Mannella and Brinton, 2006). As such, we thought that PI $3 \mathrm{~K}$ and Akt might also play a role in the $E_{2}$-induced enhancement of object recognition. To examine this issue, we first measured the effects of intrahippocampal and intracerebroventricular infusions of $\mathrm{E}_{2}$ on dorsal hippocampal PI3K and Akt phosphorylation using Western blotting. Middleaged females received infusion of vehicle (intrahippocampal or intracerebroventricular; $n=7)$, intrahippocampal $\mathrm{E}_{2}(5 \mu \mathrm{g} / \mathrm{side}$; $n=7)$, or intracerebroventricular $\mathrm{E}_{2}(10 \mu \mathrm{g} ; n=6)$, and the dorsal hippocampus was dissected bilaterally 5 min later. Levels of phosphorylated PI3K protein differed significantly among the groups $\left(F_{(2,17)}=5.29, p<0.05\right)$, such that both intrahippocampal and intracerebroventricular $\mathrm{E}_{2}$ significantly increased PI3K phosphorylation relative to vehicle $(p<0.05)$ (Fig. $4 a)$. Phosphorylated Akt protein levels also differed significantly among the groups $\left(F_{(2,16)}=15.68, p<0.001\right)$, and, again, both intrahippocampal and intracerebroventricular $\mathrm{E}_{2}$ infusions significantly increased Akt phosphorylation relative to vehicle $(p<0.001$ and $p<0.05$, respectively) (Fig. $4 b$ ). To determine whether the failure of $E_{2}$ to enhance object recognition in aged females might be attributable to an inability of $\mathrm{E}_{2}$ to activate cell signaling pathways, aged females were infused with vehicle $(n=$ $6)$ or $\mathrm{E}_{2}(n=5)$ into the dorsal hippocampus, and phosphorylation of PI3K and Akt in the dorsal hippocampus was measured 5 min later. Unlike in middle-aged females, $E_{2}$ in aged females did not increase phosphorylated PI3K (Fig. 4e) or Akt (Fig. $4 f$ ) levels relative to vehicle $\left(t_{(9)}=0.35, p>0.05\right.$ and $t_{(9)}$ $=0.27, p>0.05$, respectively).

\section{Estradiol-induced enhancement of object recognition in middle-aged females is dependent on dorsal hippocampal PI3K activation}

We next wanted to determine whether dorsal hippocampal PI3K activation was necessary for the beneficial effects of $E_{2}$ on object recognition in middle-aged females, and, therefore, we con- 

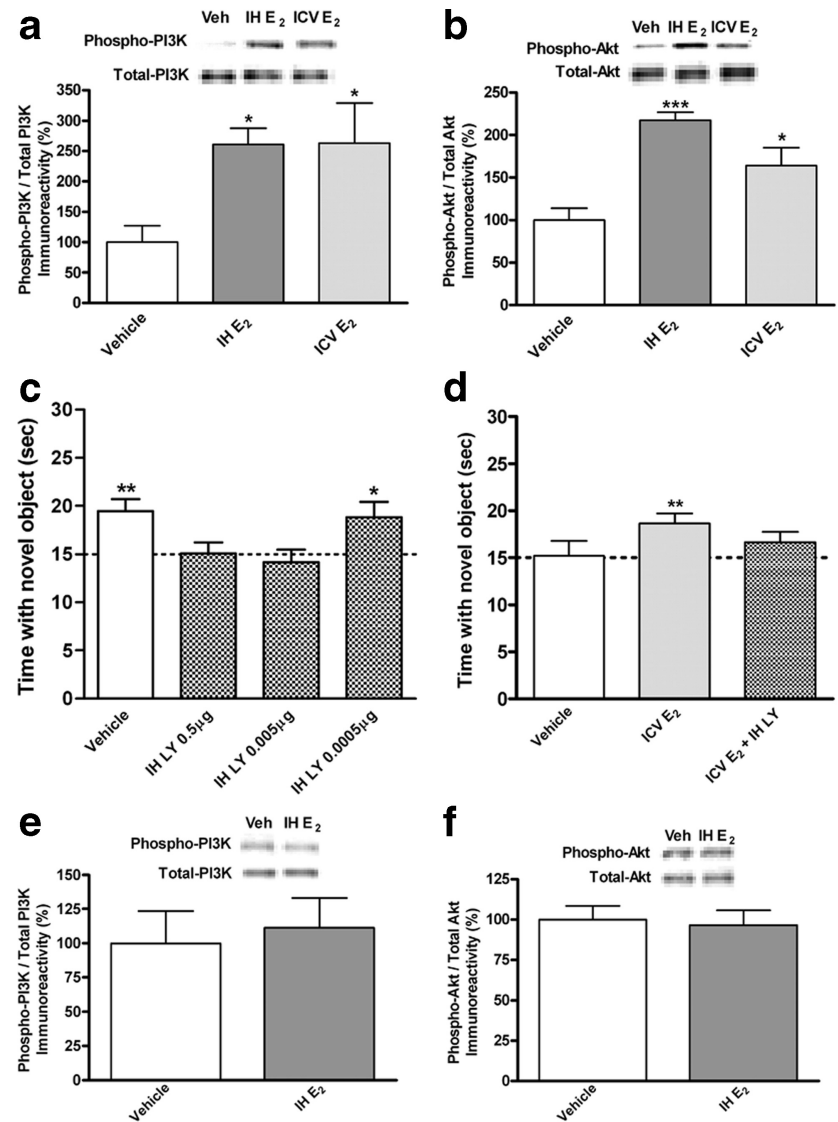

Figure 4. $\quad \boldsymbol{a}, \mathrm{PI} 3 \mathrm{~K}$ protein phosphorylation in the dorsal hippocampus of middle-aged mice significantly differed among the groups 5 min after infusion. Infusion of $E_{2}$ into either the dorsal hippocampus [intrahippocampal $(\mathrm{IH}), 5 \mu \mathrm{g} /$ side] or dorsal third ventricle [intracerebroventricular (ICV), $10 \mu \mathrm{g}$ ] significantly increased phosphorylated PI3K protein levels relative to vehicle (Veh) $\left(^{*} p<0.05\right)$. Inset, Representative Western blots showing phosphorylated and total PI3K protein levels. $\boldsymbol{b}$, Akt phosphorylation in the dorsal hippocampus of middle-aged mice significantly differed among the groups 5 min after infusion. Infusion of $E_{2}$ into either the dorsal hippocampus (5 $\mu \mathrm{g} / \mathrm{side}$ ) or dorsal third ventricle (10 $\mu \mathrm{g}$ ) significantly increased phosphorylated Akt protein levels relative to vehicle $\left({ }^{*} p<0.05,{ }^{* * *} p<0.001\right)$. Inset, Representative Western blots showing phosphorylated and total Akt protein levels. For $\boldsymbol{a}$ and $\boldsymbol{b}$, each bar represents mean \pm SEM percentage change from vehicle controls. c, Object recognition tested $24 \mathrm{~h}$ after training. Middle-aged mice receiving intrahippocampal vehicle or $0.0005 \mu \mathrm{g}$ of LY294002 (LY) per side but not those receiving 0.005 or $0.5 \mu \mathrm{g}$ of LY294002 per side spent significantly more time than chance with novel object, demonstrating that the $0.0005 \mu \mathrm{g} / \mathrm{side}$ dose of LY294002 did not impair object memory at this delay. $d$, Object recognition tested $48 \mathrm{~h}$ after training. Intrahippocampal infusions of LY294002 (0.0005 $\mu \mathrm{g} / \mathrm{side})$ blocked the beneficial effects of intracerebroventricular $E_{2}(10 \mu \mathrm{g})$ (vehicle and intracerebroventricular $E_{2}$ alone groups reprinted from Fig. 1). Mice receiving intracerebroventricular $E_{2}$ plus intrahippocampal LY294002 did not spend more time than chance with the novel object. For $\boldsymbol{c}$ and $\boldsymbol{d}$, each bar represents the mean \pm SEM time spent with the novel object $\left({ }^{*} p<0.05,{ }^{* *} p<0.01\right.$ relative to chance). $\boldsymbol{e}, \boldsymbol{f}$, Western blotting data for PI3K and Akt in aged female mice. Bilateral dorsal hippocampi were collected 5 min after dorsal hippocampal infusion of vehicle $(n=6)$ or $\mathrm{E}_{2}(5$ $\mu \mathrm{g} / \mathrm{side} ; n=5) . \mathrm{E}_{2}$ did not affect phosphorylated PI3K (e) or Akt ( $\left.\boldsymbol{f}\right)$ protein levels. For $\boldsymbol{e}$ and $\boldsymbol{f}$, each bar represents the mean \pm SEM percentage change from vehicle controls. Insets are representative Western blots for phosphorylated and total protein levels.

ducted several studies with LY294002, an inhibitor of PI3K activation. We first demonstrated that the effects of PI3K inhibition on $E_{2}$-induced enhancement object recognition did not result from general prevention of object memory formation, by identifying doses of LY294002 that did not interfere with object recognition after a $24 \mathrm{~h}$ delay. Immediately after training, middle-aged females received intrahippocampal infusions of vehicle $(n=10)$ or one of three doses of LY294002: $0.5 \mu \mathrm{g} /$ side $(n=9), 0.005$ $\mu \mathrm{g} /$ side $(n=6)$, or $0.0005 \mu \mathrm{g} /$ side $(n=8)$. Twenty-four hours later, mice receiving vehicle or $0.0005 \mu \mathrm{g}$ of LY294002 exhibited a significant preference for the novel object relative to chance $\left(t_{(9)}=3.51, p<0.01\right.$ and $t_{(7)}=2.38, p<0.05$, respectively $)$, whereas mice receiving 0.5 or $0.005 \mu \mathrm{g}$ of LY294002 did not $\left(t_{(8)}=0.07, p>0.05\right.$ and $t_{(5)}=-0.65, p>0.05$, respectively) (Fig. 4c). Because these data suggest that $0.0005 \mu \mathrm{g}$ of LY294002 did not prevent general object memory formation, the $0.0005 \mu \mathrm{g}$ dose was used for all subsequent studies.

We then infused mice intrahippocampally with LY294002 $(0.0005 \mu \mathrm{g} / \mathrm{side})$ and intracerebroventricularly with $\mathrm{E}_{2}(10 \mu \mathrm{g}$; $n=10)$ immediately after training and tested memory retention $48 \mathrm{~h}$ later. As shown in Figure $4 d$, the intracerebroventricular $\mathrm{E}_{2}$-induced memory enhancement was completely blocked by intrahippocampal LY294002 $\left(t_{(9)}=1.49, p>0.05\right.$ relative to chance), suggesting that the beneficial effects of $E_{2}$ on object recognition are dependent on dorsal hippocampal PI3K activation in middle-aged females.

\section{Estradiol-induced dorsal hippocampal ERK activation is dependent on PI3K activation in middle-aged females}

Our data indicate that both ERK and PI3K activities are required for $\mathrm{E}_{2}$ to enhance object recognition in middle-aged females, and previous studies have shown that PI3K can activate ERK either directly or indirectly (Lin et al., 2001; Perkinton et al., 2002; Chang et al., 2003; Chen et al., 2005). Therefore, we hypothesized that $\mathrm{E}_{2}$ might first activate the PI3K/Akt pathway, which could then activate ERK and lead to memory facilitation. To this end, we examined the effect of PI3K inhibition on ERK activation in the dorsal hippocampus 15 min after intracerebroventricular $\mathrm{E}_{2}$ infusion. Middle-aged mice received intrahippocampal or intracerebroventricular vehicle $(n=7)$, intracerebroventricular $\mathrm{E}_{2}$ at $10 \mu \mathrm{g}(n=6)$, or intracerebroventricular $\mathrm{E}_{2}$ at $10 \mu \mathrm{g}$ plus intrahippocampal LY294002 at $0.0005 \mu \mathrm{g}(n=8)$, and the dorsal hippocampus was dissected bilaterally $15 \mathrm{~min}$ later. Phosphorylation of p42 ERK differed among the groups $\left(F_{(2,18)}=5.07, p<\right.$ $0.05)$, but p44 ERK phosphorylation $\left(F_{(2,18)}=0.21, p>0.05\right) \mathrm{did}$ not (Fig. $5 a)$. The intracerebroventricular $\mathrm{E}_{2}$-induced increase in p42 ERK phosphorylation ( $p<0.01$ relative to vehicle) was completely blocked by intrahippocampal infusions of LY294002, suggesting that PI3K activation is upstream from ERK.

To further demonstrate that $\mathrm{E}_{2}$-induced increases in PI3K or Akt are upstream from ERK activation, we next examined PI3K and Akt phosphorylation 15 min after infusion with vehicle (intrahippocampal or intracerebroventricular, $n=6$ ), intracerebroventricular $\mathrm{E}_{2}$ at $10 \mu \mathrm{g}(n=6)$, intracerebroventricular $\mathrm{E}_{2}$ at 10 $\mu \mathrm{g}$ plus intrahippocampal U0126 at $0.5 \mu \mathrm{g} / \mathrm{side}(n=7)$, or intracerebroventricular $\mathrm{E}_{2}$ at $10 \mu \mathrm{g}$ plus intrahippocampal LY294002 at $0.0005 \mu \mathrm{g} /$ side $(n=8)$. Phosphorylated PI3K levels differed significantly among the groups $\left(F_{(3,26)}=3.00, p<0.05\right)$ (Fig. $\left.5 b\right)$; intracerebroventricular $\mathrm{E}_{2}$ treatment significantly increased PI3K phosphorylation relative to vehicle $(p<0.05)$, and this effect was completely blocked by intrahippocampal infusion of LY294002. However, the increase produced by intracerebroventricular $\mathrm{E}_{2}$ was not blocked by U0126 ( $p>0.05$ relative to vehicle) (Fig. $5 b$ ), suggesting that $\mathrm{E}_{2}$-induced $\mathrm{PI} 3 \mathrm{~K}$ activation is not dependent on ERK activation. Phosphorylated Akt levels did not significantly differ among the groups 15 min after infusion (data not shown), suggesting that the $\mathrm{E}_{2}$-induced increase in Akt phosphorylation seen 5 min after infusion is only transient. 

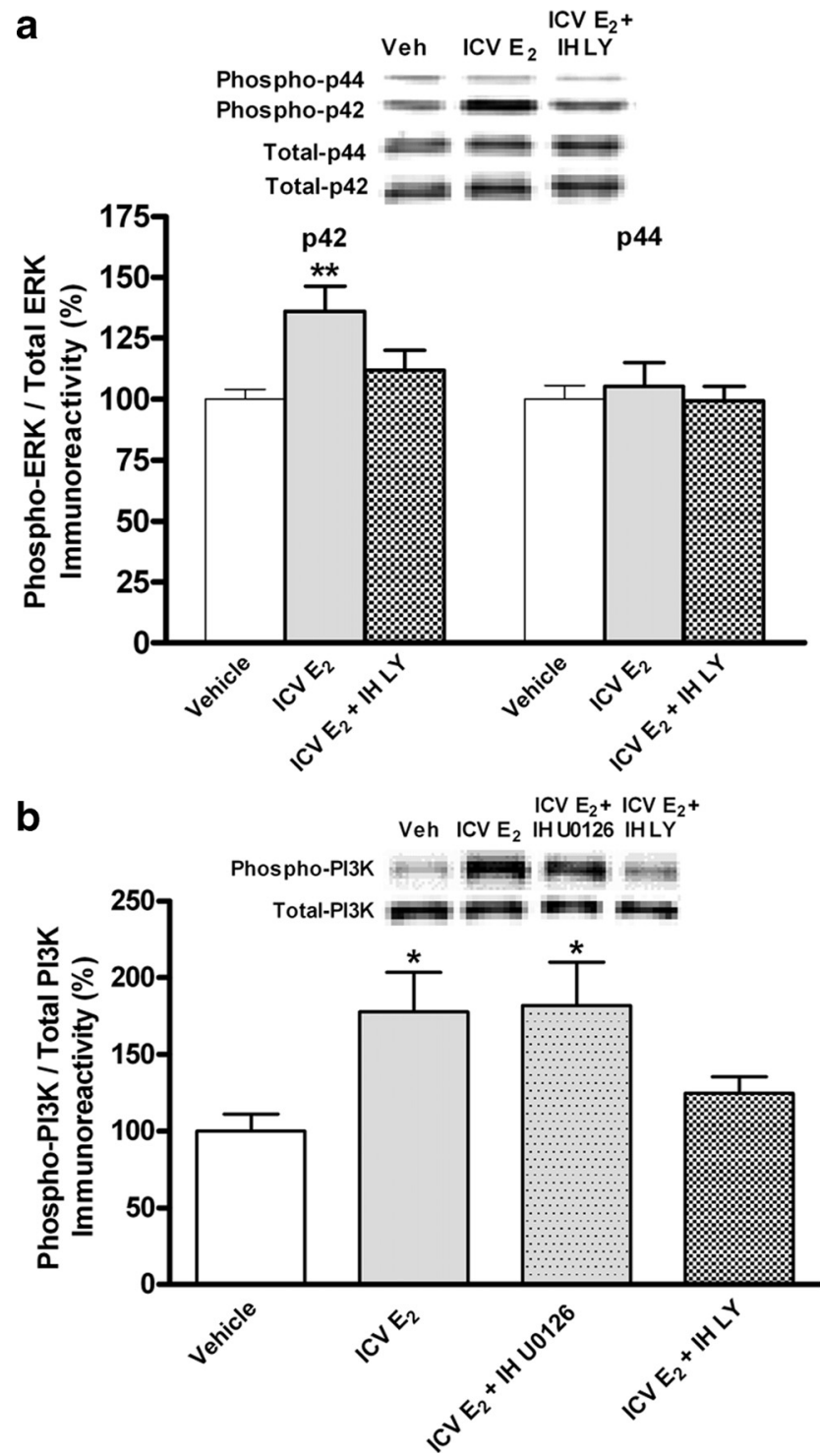

Figure 5. a, Dorsal hippocampal levels of phosphorylated p42 ERK, but not p44 ERK, were significantly increased by intracerebroventricular (ICV) $\mathrm{E}_{2}(10 \mu \mathrm{g})$ in middle-aged mice 15 min after infusion $\left({ }^{* *} p<0.01\right.$ relative to vehicle). This effect was blocked by intrahippocampal (IH) infusion of $0.0005 \mu \mathrm{g}$ of LY294002 (LY). Inset, Representative Western blots showing phosphorylated and total p42 and p44 ERK protein levels. $\boldsymbol{b}$, Dorsal hippocampal levels of phosphorylated PI3K were significantly increased by intracerebroventricular $\mathrm{E}_{2}(10 \mu \mathrm{g})$ in middle-aged mice 15 min after infusion ( ${ }^{*} p<0.05$ relative to vehicle). This increase was blocked by intrahippocampal infusion of $0.0005 \mu \mathrm{g}$ of $\mathrm{L} Y 294002$ ( $p<0.05$ relative to intracerebroventricular $E_{2}$ ) but not intrahippocampal infusion of $0.5 \mu \mathrm{g}$ of $U 0126\left({ }^{*} p<0.05\right.$ relative to vehicle). Inset, Representative Western blots showing phosphorylated and total PI3K protein levels. Each bar represents mean \pm SEM percentage change from vehicle controls.

\section{Object recognition training does not differentially affect dorsal hippocampal ERK, PI3K, or Akt in ovariectomized young and aging female mice}

Age differences in the ability of $\mathrm{E}_{2}$ to enhance object recognition and activate the ERK/MAPK and PI3K/Akt signaling pathways may be attributable to age-related decline in the function of these signaling pathways or of the ability of object recognition training to stimulate these pathways, regardless of $\mathrm{E}_{2}$ treatment. To demonstrate whether object recognition training differentially affects ERK, PI3K, and Akt levels across ages, we examined dorsal hippocampal total and phospho-ERK, -PI3K, and -Akt levels $15 \mathrm{~min}$ after object recognition training in young, middle-aged, and aged ovariectomized mice ( $n=7$ or 8 per group). Mice were habituated to the object recognition apparatus and then, $24 \mathrm{~h}$ later, were placed in the apparatus with no objects or with two identical objects. Mice with objects were allowed to accumulate $30 \mathrm{~s}$ with the objects as in our standard training protocol. Control mice without objects were yoked to spend the same amount of time in the apparatus as mice that explored objects. Dorsal hippocampi were collected bilaterally $15 \mathrm{~min}$ after training based on data from Figures $2 c$ and $5 b$ showing that $\mathrm{E}_{2}$ significantly increased ERK and PI3K phosphorylation in middle-aged females at this time point. The main effect of age was significant for phosphorylated $\mathrm{p} 42$ ERK levels $\left(F_{(2,40)}=3.978, p<0.05\right)$ (Fig. 6a), and post hoc tests indicated that levels were significantly reduced in aged females relative to young and middle-aged females $(p<0.05)$. However, the main effect of training and age $\times$ training interaction were not significant, suggesting no effect at any age of object training on p42 ERK phosphorylation measured after $15 \mathrm{~min}$. Neither the main effects of age and training nor the age $\times$ training interactions were significant for phosphorylated p44 ERK, PI3K, or Akt (Fig. 6b-d), suggesting no effect of age or training on activation of these proteins $15 \mathrm{~min}$ after training. To determine whether total protein levels were affected by age or training, we also examined total ERK, PI3K, and Akt protein levels normalized to $\beta$-actin in the same mice. Two-way ANOVA showed no significant main effects of age and training, or interactions, for total p42, p44, PI3K, or Akt levels (Fig. 7a-d). Additional two-tailed unpaired Student's $t$ tests performed between the training groups within each age (data normalized to the age-matched control group mean) also showed no significant differences in levels of all phosphorylated or total proteins, suggesting no effects within each age of training on protein levels measured after $15 \mathrm{~min}$.

\section{Discussion}

This report provides the first demonstration that intracranial $\mathrm{E}_{2}$ infusion enhances object memory consolidation in middle-aged female mice and that this effect is dependent on both PI3K and ERK activation, with an early activation of PI3K/Akt observed 5 min after infusion and a later activation of ERK 15 min after infusion. Furthermore, studies with PI3K and ERK inhibitors suggest that $\mathrm{E}_{2}$ first activates PI3K, which then activates ERK, illustrating a potential directionality of cell signaling that leads to enhanced object recognition. The involvement of PI3K signaling in estrogenic modulation of object recognition memory has not been demonstrated previously at any age, so these data also provide novel insights into the molecular mechanisms underlying these effects beyond those demonstrated previously in young females. Of importance to aging in particular, the data suggest that $\mathrm{E}_{2}$ modulates object recognition via similar signaling mechanisms in young and middle-aged females and that these mechanisms remain functional in middle-aged, but not aged, females. Although we would expect similar cell signaling mechanisms to be involved in $\mathrm{E}_{2}$-induced enhancement of other types of hippocampal memory, e.g., spatial memory, in which posttraining $\mathrm{E}_{2}$ also enhances memory consolidation in females (Packard and Teather, 1997a,b; Gresack and Frick, 2006), this generalization has yet to be tested systematically at any age.

The fact that intrahippocampal and intracerebroventricular $E_{2}$ infusion enhanced object recognition in middle-aged females is consistent with effects of systemic posttraining $E_{2}$ injections on object recognition at this age (Gresack et al., 2007a). These data are also consistent with findings from young female mice (Fernandez et al., 2008) that dorsal hippocampal ERK activation is necessary for $E_{2}$ to enhance object recognition, as demon- 

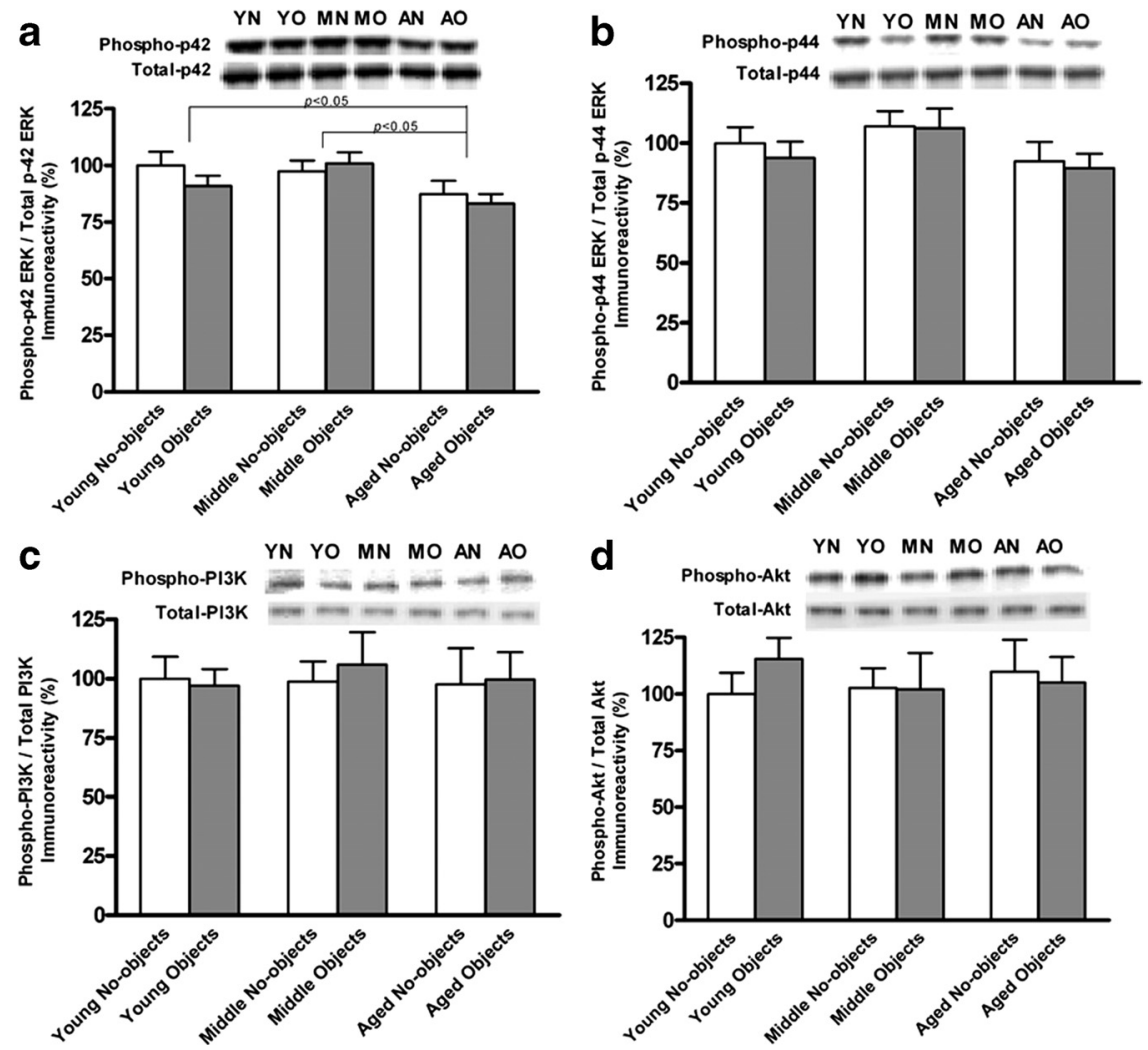

Figure 6. Western blotting data for phosphorylated ERK, PI3K, and Akt levels in young, middle-aged, and aged female mice after object recognition training. Dorsal hippocampi were collected bilaterally $15 \mathrm{~min}$ after training with objects or without objects (exploration times yoked to time for mice with objects). Each bar represents the mean \pm SEM percentage change from young no-objects controls. Insets are representative Western blots for phosphorylated and total protein levels. $\boldsymbol{a}$, For p42 ERK, the main effect of age was significant, such that phosphorylation levels were lower in aged females relative to young and middle-aged females ( $p<0.05$ for both comparisons). However, training had no effect on phosphorylated p42 ERK levels measured after 15 min. $\boldsymbol{b}-\boldsymbol{d}$, Neither age nor training significantly affected p44, PI3K, or Akt phosphorylation. Two-tailed unpaired Student's $t$ tests performed between the "no-objects" and "objects" groups within each age also showed no significant differences in levels of all phosphorylated proteins, suggesting no effects within each age of training on protein phosphorylation after $15 \mathrm{~min}$.

cle) is similar to that seen in young females (our unpublished observations), suggesting that, although the ERK response is delayed in middle-aged mice, $\mathrm{E}_{2}$ can produce a similar degree of $\mathrm{p} 42$ ERK phosphorylation in young and middle-aged females.

This study provides the first evidence that PI3K activation is necessary for $\mathrm{E}_{2}$ to enhance memory at any age. This conclusion is supported by the fact that the beneficial effects of $E_{2}$ on object recognition were blocked by intrahippocampal infusion of the PI3K inhibitor LY294002 and is consistent with literature demonstrating that hippocampal PI3K is required for several types of memory (Barros et al., 2001; Chen et al., 2005). The PI3K/Akt pathway is rapidly activated by $\mathrm{E}_{2}$ in cultured hippocampal and neocortical neurons (Singh, 2001; Yokomaku et al., 2003; Mannella and Brinton, 2006), but this report is the first to our knowledge showing that $\mathrm{E}_{2}$ can increase phosphorylation of PI3K itself. Phosphorylation of Akt is typically PI3K dependent and plays an important role in $\mathrm{E}_{2}$-induced neuroprotection (Wilson et al., 2002). $\mathrm{E}_{2}$ increases hippocampal Akt phosphorylation in vitro (Akama and McEwen, 2003; Yokomaku et al., 2003), and phosphorylated Akt is increased during the high-estradiol phase of the rodent estrous cycle (Znamensky et al., 2003; Spencer et al., 2008). Interestingly, Akt in the present study was only activated $5 \mathrm{~min}$ after $\mathrm{E}_{2}$ infusion, whereas PI3K was activated 5 and 15 min after infusion, suggesting that cell

strated by the fact that intrahippocampal U0126 blocked the beneficial effects of intracerebroventricular $\mathrm{E}_{2}$ on object recognition. Interestingly, however, the time at which $\mathrm{E}_{2}$ increased phosphorylated p42 ERK levels differed in the two ages, such that levels were increased 5 min after infusion in young females (Kuroki et al., 2000; Fernandez et al., 2008) and 15 min after infusion in middle-aged females. This delay in the temporal dynamics of $\mathrm{E}_{2}$-induced ERK activation in the dorsal hippocampus of middle-aged females may result from reduced estrogen receptor expression in the hippocampus. Hippocampal p42 ERK is activated in vitro by $\mathrm{ER} \alpha$ and $\mathrm{ER} \beta$ agonists (Zhao and Brinton, 2007) and in vivo by a form of $\mathrm{E}_{2}$ that binds to membrane-bound ERs (Fernandez et al., 2008). Hippocampal ER $\beta$ expression is decreased by 12 months of age in female rats (Yamaguchi-Shima and Yuri, 2007), and age-related alterations in the expression or function of any ER could lengthen the time necessary for $E_{2}$ to increase p42 ERK phosphorylation. The delayed ERK activation in middle-aged females also could be attributable to age-related alterations in NMDA receptors, which, in young female mice, activate ERK and are involved in the $\mathrm{E}_{2}$-inducd enhancement of object recognition (Lewis et al., 2008). In aged female rats, $E_{2}$ affects the synaptic distribution of NR2B subunits (Adams et al., 2004), which could influence downstream signaling activation. Interestingly, the magnitude of ERK activation induced by intracranial $\mathrm{E}_{2}$ in middle-aged females ( $\sim 50 \%$ over vehi- survival may not be the primary outcome of $\mathrm{E}_{2}$ treatment in our mouse model compared with ischemic models in which Akt phosphorylation can last $2 \mathrm{~h}$ after injury (Wilson et al., 2002). It should be noted that systemically injected progesterone can rapidly increase PI3K expression and phosphorylation of ERK and Akt in the hippocampus (Nilsen and Brinton, 2002, 2003; Guerra-Araiza et al., 2009), and so examining the effects of intrahippocampal infusions of $\mathrm{E}_{2}$ plus progesterone on ERK, PI3K, and Akt activation should be addressed in future studies.

The fact that $\mathrm{E}_{2}$ activated PI3K and Akt earlier (5 min) than ERK (15 min) suggests that $\mathrm{E}_{2}$ activates PI3K and Akt upstream from ERK in middle-aged females. This conclusion is supported by the fact that intrahippocampal infusion of LY294002 blocked the $\mathrm{E}_{2}$-induced activation of both PI3K and ERK, whereas intrahippocampal infusion of U0126 blocked only ERK activation. Additional support comes from studies in embryonic neocortical cell culture, in which an interaction between $\mathrm{ER} \alpha$ and the p85 regulatory subunit of PI3K leads to activation of Akt and ERK within the same neurons (Mannella and Brinton, 2006). Other studies in young adult rodents report that PI3K activates ERK directly or indirectly in the hippocampus, amygdala, and striatum (Lin et al., 2001; Perkinton et al., 2002; Chen et al., 2005), so a similar effect to that seen here would be expected in the hippocampus of young female mice. 
Collectively, the present data suggest a model of the cell signaling mechanisms in the dorsal hippocampus underlying the beneficial effects of $E_{2}$ on object recognition memory. $\mathrm{E}_{2}$, binding to membrane or nuclear ERs activates PI3K, which then activates ERK directly or indirectly through Akt. ERK activation then leads to altered gene transcription and protein translation, consistent with previous work showing that ERK activation promotes both processes (Adams and Sweatt, 2002; Kelleher et al., 2004). Altered gene transcription and protein translation then lead to enhanced memory, possibly through multiple routes such as spinogenesis, neurogenesis, and increased growth factor levels (Woolley and McEwen, 1992; Miranda et al., 1999; Tanapat et al., 1999; Bimonte-Nelson et al., 2004; Fernandez and Frick, 2004). In support of this notion, both PI3K/Akt and ERK signaling have been shown to regulate hippocampal dendritic morphology through the mammalian target of rapamycin translational pathway (Kumar et al., 2005). Although other signaling pathways may also be involved, this model provides a framework for future investigations of $\mathrm{E}_{2}$-regulated memory modulation.

Another important finding from this study is that intracranial $E_{2}$ infusion enhanced object recognition memory in middle-aged, but not aged, female mice, which is consistent with findings from other studies that have compared effects of $E_{2}$ on hippocampal memory in middle-aged and aged female rodents (Savonenko and Markowska, 2003; Gresack et al., 2007a; Talboom et al., 2008). The present and previous studies support the critical period hypothesis, which maintains that $\mathrm{E}_{2}$ benefits cognition only in recently menopausal women (Maki, 2006; Sherwin and Henry, 2008). The decreased responsiveness of the aged female hippocampus to $\mathrm{E}_{2}$ may result from age-related reductions in hippocampal ER immunoreactivity and mRNA levels (Adams et al., 2002; Mehra et al., 2005; Yamaguchi-Shima and Yuri, 2007) and/or, as demonstrated in this report, by impairments in cell signaling. We show here that dorsal hippocampal ERK and PI3K activation are necessary for $\mathrm{E}_{2}$ to enhance object recognition in middle-aged females, and, thus, the failure of a single posttraining $\mathrm{E}_{2}$ injection to enhance object recognition in aged females may result from the inability of $\mathrm{E}_{2}$ to activate PI3K (Fig. $4 e$ ) or of age-related reductions in phospho-p42 ERK protein (Fig. 6a). However, it should be noted that aged female mice are not completely unresponsive to $E_{2}$, because $E_{2}$ can enhance various forms of hippocampal memory in aged rodents (Miller et al., 1999; Frick et al., 2002; Heikkinen et al., 2002; Vaucher et al., 2002; Foster et al., 2003), although the response of aged females to $E_{2}$ is influenced by numerous factors, including timing of treatment relative to testing (e.g., before and after training), priming (Savonenko and Markowska, 2003), duration of treatment, and dose (for review, see Frick, 2009). In particular, timing and treatment duration may be important factors for object recognition, because chronic pretraining $\mathrm{E}_{2}$ treatment improves object recognition in aged female
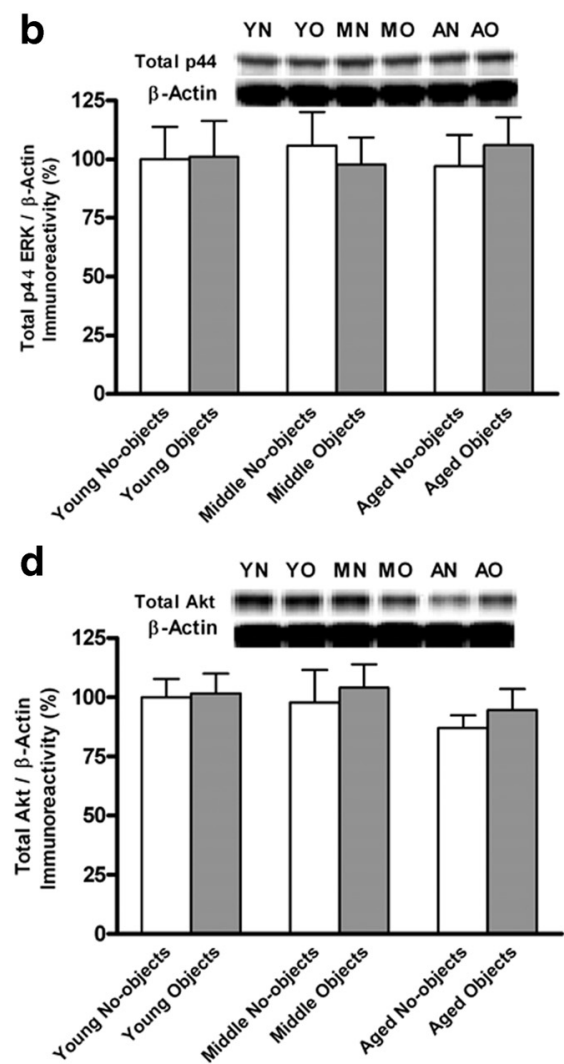

Figure 7. Western blotting data for total ERK, PI3K, and Akt in the young, middle-aged, and aged female mice shown in Figure 6 . Each bar represents the mean \pm SEM percentage change from young no-objects controls. Insets are representative Western Two-tailed unpaired Student's $t$ tests performed between the "no-objects" and "objects" groups within each age also showed no significant differences of training in levels of all four proteins after $15 \mathrm{~min}$.

mice (Vaucher et al., 2002). Dose may also be an issue here, since the doses used in this study may have been too low to enhance memory in aged females. Although this explanation is less likely given that both systemic (Gresack et al., 2007a,b) and intracranial (present study) $\mathrm{E}_{2}$ treatments fail to enhance object recognition in aged female mice, testing higher intracranial doses should help resolve this issue.

Finally, the data also indicate that, in the absence of $\mathrm{E}_{2}$, object recognition training does not activate the ERK/MAPK and PI3K/ Akt pathways at any age after $15 \mathrm{~min}$. This finding might suggest that object training does not activate these pathways and that the $\mathrm{E}_{2}$-induced enhancement of object recognition is mediated by a different set of cellular mechanisms than those that normally take place during object memory consolidation. Although this possibility cannot be conclusively discounted at present, it is not supported by previous studies in young mice showing that ERK phosphorylation in whole hippocampus is increased $10 \mathrm{~min}$ (Wang et al., 2004) or $30 \mathrm{~min}$ (Goeldner et al., 2008) after object recognition training. Moreover, our own data from young (Fernandez et al., 2008) and middle-aged (present study) vehicle-treated females shows that preventing ERK or PI3K activation in the absence of $\mathrm{E}_{2}$ blocks $24 \mathrm{~h}$ object recognition. Together, these studies indicate that object recognition training activates ERK and that preventing this activation blocks learning. However, ERK and PI3K may be activated more slowly in middle-aged females, and, thus, the 15 min time point may have been too soon to observe $\mathrm{E}_{2}$-induced increases in these enzymes. Alternatively, ERK and PI3K may be activated more slowly in the 
absence of $E_{2}$, regardless of age, with the more rapid $E_{2}$-induced activation leading to longer-lasting memory (i.e., $48 \mathrm{~h}$ rather than $24 \mathrm{~h}$ ). Measuring protein levels at times longer than $15 \mathrm{~min}$ would help demonstrate the time course of training-induced activation of these signaling pathways.

In conclusion, the present study demonstrates that the $\mathrm{E}_{2}$ induced enhancement of object recognition in middle-aged female mice is dependent on PI3K and ERK activation in the dorsal hippocampus. These data provide the first evidence that hippocampal cell signaling molecules are critically necessary for estrogenic enhancement of object memory consolidation in middle-aged females. Interestingly, middle-aged females are responsive to the same doses of $\mathrm{E}_{2}$ as young females, and the signaling pathways that mediate effects of $\mathrm{E}_{2}$ on object recognition are similar in young and middle-aged females, suggesting that the mechanisms through which $\mathrm{E}_{2}$ modulates object recognition in females remain essentially intact during middle age. The failure of $E_{2}$ to enhance object recognition in aged females may be attributable to its inability to activate dorsal hippocampal PI3K and ERK. Together, the present data provide important new insights into the molecular mechanisms underlying estrogenic modulation of memory in aging females that could be pivotal to the design of future hormone therapies.

\section{References}

Adams JP, Sweatt JD (2002) Molecular psychology: roles for the ERK MAP kinase cascade in memory. Annu Rev Pharmacol Toxicol 42:135-163.

Adams MM, Fink SE, Shah RA, Janssen WG, Hayashi S, Milner TA, McEwen BS, Morrison JH (2002) Estrogen and aging affect the subcellular distribution of estrogen receptor- $\alpha$ in the hippocampus of female rats. J Neurosci 22:3608-3614.

Adams MM, Fink SE, Janssen WG, Shah RA, Morrison JH (2004) Estrogen modulates synaptic $N$-methyl-D-aspartate receptor subunit distribution in the aged hippocampus. J Comp Neurol 474:419-426.

Akama KT, McEwen BS (2003) Estrogen stimulates postsynaptic density-95 rapid protein synthesis via the Akt/protein kinase B pathway. J Neurosci 23:2333-2339.

Baker KB, Kim JJ (2002) Effects of stress and hippocampal NMDA receptor antagonism on recognition memory in rats. Learn Mem 9:58-65.

Barros DM, Mello e Souza T, de Souza MM, Choi H, DeDavid e Silva T, Lenz G, Medina JH, Izquierdo I (2001) LY294002, an inhibitor of phosphoinositide 3-kinase given into rat hippocampus impairs acquisition, consolidation and retrieval of memory for one-trial step-down inhibitory avoidance. Behav Pharmacol 12:629-634.

Bi R, Foy MR, Thompson RF, Baudry M (2003) Effects of estrogen, age, and calpain on MAP kinase and NMDA receptors in female rat brain. Neurobiol Aging 24:977-983.

Bimonte-Nelson HA, Nelson ME, Granholm AC (2004) Progesterone counteracts estrogen-induced increases in neurotrophins in the aged female rat brain. Neuroreport 15:2659-2663.

Chang F, Steelman LS, Lee JT, Shelton JG, Navolanic PM, Blalock WL, Franklin RA, McCubrey JA (2003) Signal transduction mediated by the Ras/Raf/ MEK/ERK pathway from cytokine receptors to transcription factors: potential targeting for therapeutic intervention. Leukemia 17:1263-1293.

Chen X, Garelick MG, Wang H, Lil V, Athos J, Storm DR (2005) PI3 kinase signaling is required for retrieval and extinction of contextual memory. Nat Neurosci 8:925-931.

Clark RE, Zola SM, Squire LR (2000) Impaired recognition memory in rats after damage to the hippocampus. J Neurosci 20:8853-8860.

Fan L, Hanbury R, Pandey SC, Cohen RS (2008) Dose and time effects of estrogen on expression of neuron-specific protein and cyclic AMP response element-binding protein and brain region volume in the medial amygdala of ovariectomized rats. Neuroendocrinology 88:112-126.

Fernandez SM, Frick KM (2004) Chronic oral estrogen affects memory and neurochemistry in middle-aged female mice. Behav Neurosci 118: $1340-1351$

Fernandez SM, Lewis MC, Pechenino AS, Harburger LL, Orr PT, Gresack JE, Schafe GE, Frick KM (2008) Estradiol-induced enhancement of object memory consolidation involves hippocampal ERK activation and membrane-bound estrogen receptors. J Neurosci 28:8660-8667.

Foster TC, Sharrow KM, Kumar A, Masse J (2003) Interaction of age and chronic estradiol replacement on memory and markers of brain aging. Neurobiol Aging 24:839-852.

Frick KM (2009) Estrogens and age-related memory decline in rodents: What have we learned and where do we go from here? Horm Behav 55:2-23.

Frick KM, Gresack JE (2003) Sex differences in the behavioral response to spatial and object novelty in adult C57BL/6 mice. Behav Neurosci 117: 1283-1291.

Frick KM, Fernandez SM, Bulinski SC (2002) Estrogen replacement improves spatial reference memory and increases hippocampal synaptophysin in aged female mice. Neuroscience 115:547-558.

Geltz NR, Augustine JA (1998) The p85 and p110 subunits of phosphatidylinositol 3-kinase are substrates, in vitro, for a constitutively asssociated protein kinase in platelets. Blood 91:930-939.

Goeldner C, Reiss D, Wichmann J, Meziane H, Kieffer BL, Ouagazzal AM (2008) Nociceptin receptor impairs recognition memory via interaction with NMDA receptor-dependent mitogen-activated protein kinase/extracellular signal-regulated kinase signaling in the hippocampus. J Neurosci 28:2190-2198.

Gooney M, Messaoudi E, Maher FO, Bramham CR, Lynch MA (2004) BDNF-induced LTP in dentate gyrus is impaired with age: Analysis of changes in cell signaling events. Neurobiol Aging 25:1323-1331.

Gresack JE, Frick KM (2004) Environmental enrichment reduces the mnemonic and neural benefits of estrogen. Neuroscience 128:459-471.

Gresack JE, Frick KM (2006) Post-training estrogen enhances spatial and object memory consolidation in female mice. Pharmacol Biochem Behav 84:112-119.

Gresack JE, Kerr KM, Frick KM (2007a) Life-long environmental enrichment differentially affects the mnemonic response to estrogen in young, middle-aged, and aged female mice. Neurobiol Learn Mem 88:393-408.

Gresack JE, Kerr KM, Frick KM (2007b) Short-term environmental enrichment decreases the mnemonic response to estrogen in young, but not aged, female mice. Brain Res 1160:91-101.

Guerra-Araiza C, Amorim MA, Pinto-Almazán R, Gonzáles-Arenas A, Campos MG, Garcia-Segura LM (2009) Regulation of the phosphoinositide-3 kinase and mitogen-activated protein kinase signaling pathways by progesterone and its reduced metabolites in the rat brain. J Neurosci Res 87:470-481.

Heikkinen T, Puoliväli J, Liu L, Rissanen A, Tanila H (2002) Effects of ovariectomy and estrogen treatment on learning and hippocampal neurotransmitters in mice. Horm Behav 41:22-32.

Henderson VW, Benke KS, Green RC, Cupples LA, Farrer LA (2005) Postmenopausal hormone therapy and Alzheimer's disease risk: Interaction with age. J Neurol Neurosurg Psychiatry 76:103-105.

Horwood JM, Dufour F, Laroche S, Davis S (2006) Signalling mechanisms mediated by the phosphoinositide 3-kinase/Akt cascade in synaptic plasticity and memory in the rat. Eur J Neurosci 23:3375-3384.

Kelleher RJ 3rd, Govindarajan A, Jung HY, Kang H, Tonegawa S (2004) Translational control by MAPK signaling in long-term synaptic plasticity and memory. Cell 116:467-479.

Kelly A, Lynch MA (2000) Long-term potentiation in dentate gyrus of the rat is inhibited by the phosphoinositide 3-kinase inhibitor, wortmannin. Neuropharmacology 39:643-651.

Kumar V, Zhang MX, Swank MW, Kunz J, Wu GY (2005) Regulation of dendritic morphogenesis by Ras-PI3K-Akt-mTOR and Ras-MAPK signaling pathways. J Neurosci 25:11288-11299.

Kuroki Y, Fukushima K, Kanda Y, Mizuno K, Watanabe Y (2000) Putative membrane-bound estrogen receptors possibly stimulate mitogen-activated protein kinase in the rat hippocampus. Eur J Pharmacol 400:205-209.

Lewis MC, Kerr KM, Orr PT, Frick KM (2008) Estradiol-induced enhancement of object memory consolidation involves NMDA receptors and protein kinase $\mathrm{A}$ in the dorsal hippocampus of female C57BL/6 mice. Behav Neurosci 122:716-721.

Lin CH, Yeh SH, Lin CH, Lu KT, Leu TH, Chang WC, Gean PW (2001) A role for the PI-3 kinase signaling pathway in fear conditioning and synaptic plasticity in the amygdala. Neuron 31:841-851.

Maki PM (2006) Hormone therapy and cognitive function: Is there a critical period for benefit? Neuroscience 138:1027-1030.

Mannella P, Brinton RD (2006) Estrogen receptor protein interaction with phosphatidylinositol 3-kinase leads to activation of phosphorylated Akt 
and extracellular signal-regulated kinase $1 / 2$ in the same population of cortical neurons: a unified mechanism of estrogen action. J Neurosci 26:9439-9447.

Mehra RD, Sharma K, Nyakas C, Vij U (2005) Estrogen receptor $\alpha$ and $\beta$ immunoreactive neurons in normal adult and aged female rat hippocampus: a qualitative and quantitative study. Brain Res 1056:22-35.

Miller MM, Hyder SM, Assayag R, Panarella SR, Tousignant P, Franklin KBJ (1999) Estrogen modulates spontaneous alternation and the cholinergic phenotype in the basal forebrain. Neuroscience 91:1143-1153.

Milner TA, McEwen BS, Hayashi S, Li CJ, Reagan LP, Alves SE (2001) Ultrastructural evidence that hippocampal alpha estrogen receptors are located at extranuclear sites. J Comp Neurol 429:355-371.

Milner TA, Ayoola K, Drake CT, Herrick SP, Tabori NE, McEwen BS, Warrier S, Alves SE (2005) Ultrastructural localization of estrogen receptor beta immunoreactivity in the rat hippocampal formation. J Comp Neurol 491:81-95.

Miranda P, Williams CL, Einstein G (1999) Granule cells in aging rats are sexually dimorphic in their response to estradiol. J Neurosci 19:33163325.

Nilsen J, Brinton RD (2002) Impact of progestins on estrogen-induced neuroprotection: synergy by progesterone and 19-norprogesterone and antagonism by medroxyprogesterone acetate. Endocrinology 143:205-212.

Nilsen J, Brinton RD (2003) Divergent impact of progesterone and medroxyprogesterone acetate (Provera) on nuclear mitogen-activated protein kinase signaling. Proc Natl Acad Sci U S A 100:10506-10511.

Packard MG, Teather LA (1997a) Intra-hippocampal estradiol infusion enhances memory in ovariectomized rats. Neuroreport 8:3009-3013.

Packard MG, Teather LA (1997b) Posttraining estradiol injections enhance memory in ovariectomized rats: cholinergic blockade and synergism. Neurobiol Learn Mem 68:172-188.

Paxinos G, Franklin KBJ (2003) The mouse brain in stereotaxic coordinates, Ed 2. San Diego: Academic.

Perkinton MS, Ip JK, Wood GL, Crossthwaite AJ, Williams RJ (2002) Phosphatidylinositol 3-kinase is a central mediator of NMDA receptor signalling to MAP kinase (Erk1/2), Akt/PKB and CREB in striatal neurones. J Neurochem 80:239-254.

Rapp SR, Espeland MA, Shumaker SA, Henderson VW, Brunner RL, Manson JE, Gass MLS, Stefanick ML, Lane DS, Hays J, Johnson KC, Coker LH, Dailey M, Bowen D (2003) Effect of estrogen plus progestin on global cognitive function in postmenopausal women. The Women's Health Initiative Memory Study: a randomized controlled trial. JAMA 289:26632672.

Rossouw JE, Anderson GL, Prentice RL, LaCroix AZ, Kooperberg C, Stefanick ML, Jackson RD, Beresford SA, Howard BV, Johnson KC, Kotchen JM, Ockene J (2002) Risks and benefits of estrogen plus progestin in healthy postmenopausal women. JAMA 288:321-333.

Savonenko AV, Markowska AL (2003) The cognitive effects of ovariectomy and estrogen replacement are modulated by aging. Neuroscience 119:821-830.

Sherwin BB, Henry JF (2008) Brain aging modulates the neuroprotective effects of estrogen on selective aspects of cognition in women: a critical review. Front Neuroendocrinol 29:88-113.

Shumaker SA, Legault C, Kuller L, Rapp SR, Thal L, Lane DS, Fillit H, Stefanick
ML, Hendrix SL, Lewis CE, Masaki K, Coker LH (2004) Conjugated equine estrogens and incidence of probable dementia and mild cognitive impairment in postmenopausal women: Women's Health Initiative Memory Study. JAMA 291:2947-2958.

Singh M (2001) Ovarian hormones elicit phosphorylation of Akt and extracellular-signal regulated kinase in explants of the cerebral cortex. Endocrine 14:407-415.

Spencer JL, Waters EM, Milner TA, McEwen BS (2008) Estrous cycle regulates activation of hippocampal Akt, LIM kinase, and neurotrophin receptors in C57BL/6 mice. Neuroscience 155:1106-1119.

Talboom JS, Williams BJ, Baxley ER, West SG, Bimonte-Nelson HA (2008) Higher levels of estradiol replacement correlate with better spatial memory in surgically menopausal young and middle-aged rats. Neurobiol Learn Mem 90:155-163.

Tanapat P, Hastings NB, Reeves AJ, Gould E (1999) Estrogen stimulates a transient increase in the number of new neurons in the dentate gyrus of the adult female rat. J Neurosci 19:5792-5801.

Tsuda M, Ueno H, Kataoka A, Tozaki-Saitoh H, Inoue K (2008) Activation of dorsal horn microglia contributes to diabetes-induced tactile allodynia via extracellular signal-regulated protein kinase signaling. Glia 56:378386.

Vaucher E, Reymond I, Najaffe R, Kar S, Quirion R, Miller MM, Franklin KBJ (2002) Estrogen effects on object memory and cholinergic receptors in young and old female mice. Neurobiol Aging 23:87-95.

Wang H, Ferguson GD, Pineda VV, Cundiff PE, Storm DR (2004) Overexpression of type-1 adenyly cyclase in mouse forebrain enhances recognition memory and LTP. Nat Neurosci 7:635-642.

Williams B, Granholm AC, Sambamurti K (2007) Age-dependent loss of NGF signaling in the rat basal forebrain is due to disrupted MAPK activation. Neurosci Lett 413:110-114.

Williams BJ, Bimonte-Nelson HA, Granholm-Bentley AC (2006) ERKmediated NGF signaling in the rat septo-hippocampal pathway diminishes with age. Psychopharmacology 188:605-618.

Wilson ME, Liu Y, Wise PM (2002) Estradiol enhances Akt activation in cortical explant cultures following neuronal injury. Mol Brain Res 102:48-54.

Woolley CS, McEwen BS (1992) Estradiol mediates fluctuation in hippocampal synapse density during the estrous cycle in the adult rat. J Neurosci 12:2549-2554.

Yamaguchi-Shima N, Yuri K (2007) Age-related changes in the expression of ER- $\beta$ mRNA in the female rat brain. Brain Res 1155:34-41.

Yokomaku D, Numakawa T, Numakawa Y, Suzuki S, Matsumoto T, Adachi N, Nishio C, Taguchi T, Hatanaka H (2003) Estrogen enhances depolarizationinduced glutamate release through activation of phosphatidylinositol 3-kinase and mitogen-activated protein kinase in cultured hippocampal neurons. Mol Endocrinol 17:831-844.

Zhao L, Brinton RD (2007) Estrogen receptor $\alpha$ and $\beta$ differentially regulate intracellular $\mathrm{Ca}^{2+}$ dynamics leading to ERK phosphorylation and estrogen neuroprotection in hippocampal neurons. Brain Res 1172:48-59.

Znamensky V, Akama KT, McEwen BS, Milner TA (2003) Estrogen levels regulate the subcellular distribution of phosphorylated Akt in hippocampal CA1 dendrites. J Neurosci 23:2340-2347. 